\title{
Risk Factors for Atherosclerosis in an Elderly out Patient Population in the City of São Paulo
}

\author{
Yolanda Maria Garcia Alencar, Eurico Thomaz de Carvalho F, Sérgio Márcio Pacheco Paschoal, \\ José Antonio Esper Curiati, Wong Chiu Ping, Júlio Litvoc
}

São Paulo, SP - Brazil

\begin{abstract}
Objective - To analyze in out clinic elderly patients of both sexes for the prevalence of risk factors for atherosclerosis and study their association with the complications of atherosclerosis.
\end{abstract}

Methods - Five hundred and sixteen outpatients, 152 men and 364 women, 60 years or older, were studied. The prevalences of hypertension, dyslipidemia, diabetes mellitus, cigarette smoking and obesity were determined in both sexes and compared using the chi-square test. The association between these factors and the presence of atherosclerotic complications was analyzed by logistic regression.

Results - The comparative analysis of the factors in both sexes showed that hypertension, total cholesterol $\geq 240 \mathrm{mg} /$ $d L, L D L$-cholesterol $\geq 160 \mathrm{mg} / \mathrm{dL}$, and body mass index $>27.5$ were more frequent among women, but HDL-cholesterol $<35 \mathrm{mg} / \mathrm{dL}$ and cigarette smoking were more frequent among men, and no difference occurred between sexes in relation to the frequency of triglycerides $\geq 250 \mathrm{mg} / \mathrm{dL}$ and diabetes mellitus. After adjustment of the variables in the regression model, we observed that in the total of elderly patients, riskfactors for complications of atherosclerosis were: triglycerides $\geq 250 \mathrm{mg} / d L$, hypertension, and male sex. Among men, the risk factors were: $L D L$-cholesterol $\geq 160 \mathrm{mg} /$ $d L$, diabetes mellitus, $H D L$-cholesterol $<35 \mathrm{mg} / d L$ and hypertension. Among women, the risk factors were: tryglicerides $\geq 250 \mathrm{mg} / \mathrm{dL}$ and hypertension.

Conclusion - The results showed that, in the elderly, the risk factors for atherosclerosis persist, but with different behaviors between men and women. The study suggests that the relative importance of the risk factors can change with the aging process.

Key words: risk factors, atherosclerosis, elderly

Hospital das Clínicas da Faculdade de Medicina da Universidade de São Paulo Mailing address: Eurico Thomaz de Carvalho $F^{\circ}$ - Rua Frei Caneca, 1212 - conj. 92 - 01307-002 - São Paulo, SP - Brazil
Cardiovascular disease as a complication of atherosclerosis is today the most important cause of morbidity and mortality among elderly people especially in the developed countries ${ }^{1-3}$. Although in the earlier decades of life women have a lower prevalence of cardiovascular disease, the latter increases with age, reaching a similar level to that of men around the age of $75^{4-6}$.

The same tendency has been observed in Brazil. According to the Sistema Estadual de Análise de Dados (SEADE) and the Instituto Brasileiro de Geografia e Estatística (IBGE), in 1995, in the city of São Paulo coronary artery disease was more prevalent in men up to the age of 75 years, but the prevalence became similar in both sexes after that age ${ }^{7}$.

Atherosclerosis is a disease in which multiple factors contribute to the degeneration of the arterial wall. It is evident that intensity and duration of injury define the severity of the alterations. Many risk factors were identified as having influence on the progression of atherosclerosis, mainly age, sex, heredity, diet composition, tobacco smoking, physical activity, obesity, systemic arterial hypertension, dyslipidemia, diabetes mellitus, plasma fibrinogen levels, hyperhomocysteinemia, left ventricular hypertrophy and psycho-social factors.

Researchers in the area agree that an order of risk factors exists and, in addition to age, sex, and heredity, hypertension, dyslipidemia, diabetes mellitus, tobacco smoking, and obesity must also be considered as major risk factors and deserve more attention. Most of the research, however, involves individuals of middle age and, more specifically, white males ${ }^{8}$. More recently, population studies have been aiming at the behavior of risk factors in the elderly, and some of these studies have cast doubt on their importance at this age 1,29-12. $^{\text {. }}$

The goal of the present study was analyze in elderly individuals of both sexes the prevalence of the major risk factors and their correlation with atherosclerotic complications.

\section{Methods}

A group of 859 outpatients from the Geriatric Service of Hospital das Clínicas of the University of São Paulo Medical 
School, aged 60 or older, were randomly selected, being 245 males $(28.5 \%)$ and 614 females $(71.5 \%)$, during the years 1992 through 1994. All the patients enrolled in the outpatient department could potentially enter the study, and the patients were chosen alternately without any special selection criteria. The proportion of men and women was similar to that observed in the outpatient clinic.

Through the medical records and by direct interview of the patients, the following risk factors were analyzed: sex, systemic arterial hypertension, dyslipidemia, diabetes mellitus, tobacco smoking, and obesity. For the present study, we included only the elderly patients who had all the risk factors properly studied, or 516 patients, 152 (29.5\%) males and $364(70.5 \%)$ females. The patients were analyzed according to the presence or not of atherosclerotic complications. Three territories of atherosclerotic complications were considered: coronary, cerebral, and peripheral. Patients with angina pectoris, previous myocardial infarction, coronary angioplasty, or bypass surgery were included in the coronary artery disease group. Patients with previous cerebral infarction or clinical signs of transient ischemic attacks were included in the cerebrovascular disease group. Claudication with peripheral pulse reduction and surgical treatment for the reestablishment of arterial circulation were the criteria of inclusion in the peripheral artery disease group.

The diagnosis of systemic arterial hypertension was made in individuals with systolic pressure of $160 \mathrm{mmHg}$ or higher, with diastolic pressure of $95 \mathrm{mmHg}$ or higher, or with both of these ${ }^{13}$, with a minimum of two measurements on two different visits, or in patients already under drug treatment. The blood pressure was determined with the patient in the supine position, after resting for at least three minutes.

The diagnosis of dyslipidemia was based on total cholesterol (TC) levels of $240 \mathrm{mg} / \mathrm{dL}$ or higher, low-density lipoprotein cholesterol (LDL-C) levels of $160 \mathrm{mg} / \mathrm{dL}$ or higher, high-density lipoprotein cholesterol (HDL-C) lower than $35 \mathrm{mg} / \mathrm{dL}$ or triglycerides levels of $250 \mathrm{mg} / \mathrm{dL}$ or higher. Total cholesterol and triglycerides levels were determined by enzymatic methods ${ }^{14}$ and HDL-cholesterol levels were determined by the Warnick-Albers method ${ }^{15}$. The other fractions were calculated as follows ${ }^{16}$ : very low-density lipoprotein cholesterol (VLDL-C) by the division of triglycerides/5, when triglycerides levels were lower than $400 \mathrm{mg} / \mathrm{dL}$ and LDL-cholesterol by the following equation: LDL-C=TC(HDL-C+VLDL-C).

Diabetes mellitus was diagnosed when fasting plasma glucose levels were above $140 \mathrm{mg} / \mathrm{dL}$ on at least two occasions, or when the patient was under drug treatment. Plasma glucose levels were determined by colorimetry after precipitation ${ }^{17}$. Blood samples for glucose and lipid determinations were obtained after 10 to 12 hours of fasting.

The patients were divided in two groups according to their smoking habits: smokers or nonsmokers. Patients who were smokers in the past, but not presently, were excluded.

Obesity was defined by body mass index or Quetelet index, obtained by the formula: [body mass index = weight $(\mathrm{kg}) /$ height $\left.(\mathrm{m})^{2}\right]^{18,19}$. The diagnosis of obesity was made when body mass index was greater than 27.5 . For weight and height determination, the patients wore light clothes and were barefoot. Height was measured with the patient in the upright position, with the patient's back against a wall.

The comparative analysis of the prevalences of the factors among men and women was done by the chi-square $\left(X^{2}\right)$ test, and the comparison between the mean of ages by Student's $t$ test with the significance level established at 0.05 .

The relationship of each risk factor with atherosclerotic complications was defined by logistic regression analysis ${ }^{20}$.

Initially, a univariate analysis was performed as a strategy for the selection of variables to be adjusted in a logistic regression model. In the final analysis, we included in the model the variables with the Pearson's p value of up to 0.494 for the men, up to 0.503 for the women, and up to 0.560 for the total of the elderly patients, indicating that the number of variables was small and that clinical interest existed for testing them in the model.

Each one of the logistic regression models, namely, that of the men, the women, and the total of the elderly patients was adjusted by means of a forward stepwise model technique. For example, in the analysis of the total of the elderly patients, we first included the variables sex and systemic arterial hypertension that had small p values in univariate analysis. In the analysis of the men, the first variables included were diabetes mellitus and systemic arterial hypertension; in the analysis of the women, the first variables were systemic arterial hypertension and triglycerides. Subsequently, the other variables were included, following a sequence of the $\mathrm{p}$ values obtained in univariate analysis. In this manner, we tried to estimate the independent effect of each variable adjusted to the model, controlling the respective confounding effects. The likelihood ratio test of each final model was performed, defining its significance, which permitted the evaluation of the adequacy of the model.

\section{Results}

Among the 516 elderly patients studied, the average age was 75.6 years, with no statistically significant difference between men and women ( $\mathrm{p}=0.276)$.

The prevalences of the various risk factors are shown in figure 1 and in the first two left columns of the tables I, II, and III.

The comparative analysis of the prevalences of the variables among the elderly patients of both sexes showed that systemic arterial hypertension $(\mathrm{p}=0.05)$, total cholesterol $\geq 240 \mathrm{mg} / \mathrm{dL}$ ( $\mathrm{p}=0.001$ ), LDL-cholesterol $\geq 160 \mathrm{mg} / \mathrm{dL}$ ( $\mathrm{p}=-$ 0.012 ), and body mass index $>27.5(\mathrm{p}=0.009)$ were more frequent among women, HDL-cholesterol $<35 \mathrm{mg} / \mathrm{dL}$ ( $\mathrm{p}=0.024)$ and tobacco smoking ( $\mathrm{p}=0.044)$ were more frequent among men, and no significant difference was noted in relation to triglycerides $(\mathrm{p}=0.458)$ and diabetes mellitus $(\mathrm{p}=0.706)$.

Atherosclerotic complications were observed in 110 $(21.3 \%)$ elderly patients, being $45(29.6 \%)$ among men and $65(17.9 \%$ ) among women (table I), showing that the risk was significantly greater among men [odds ratio $(\mathrm{OR})=1.93$; $\mathrm{p}=0.003$; confidence interval of $\left.95 \%\left(\mathrm{CI}_{95 \%}\right)=1.22-3.07\right]$. 


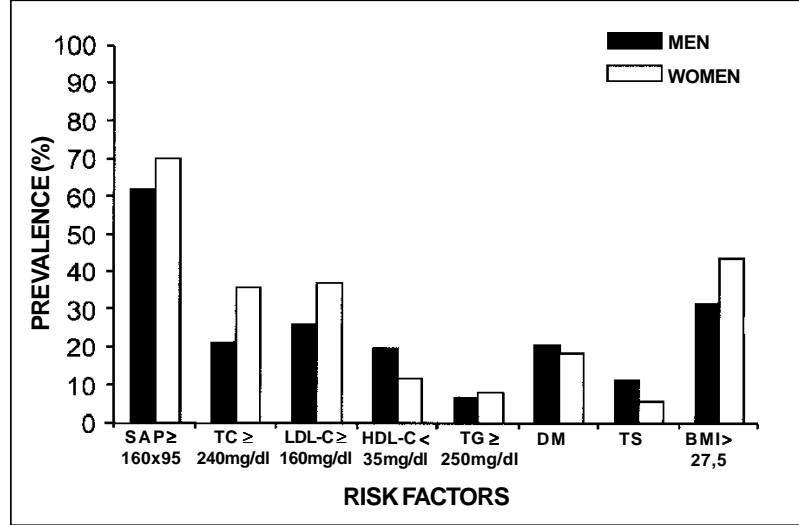

Fig. 1 - Prevalence of the risk factors for atherosclerosis in the elderly (152 men and 364 women). SAP- systemic arterial pressure; TC- total cholesterol; LDL-C- LDLcholesterol; HDL-C- HDL-cholesterol; TG- triglycerides; DM- Diabetes mellitus; TS- tobacco smoking habit; BMI- body mass index.

In all the elderly patients, an association existed between complications of atherosclerosis and systemic arterial hypertension (odds ratio $=1.97$ ), triglycerides levels $\geq 250 \mathrm{mg} / \mathrm{dL}$ (odds ratio $=2.05$ ), diabetes mellitus (odds ratio $=1.69$ ), HDLcholesterol level $<35 \mathrm{mg} / \mathrm{dL}$ (odds ratio $=1.70$ ), the last one with a p value of 0.056 (table I).

Among men, an association existed between complications of atherosclerosis and systemic arterial hypertension (odds ratio $=2.51)$, LDL- cholesterol level $\geq 160 \mathrm{mg} / \mathrm{dL}$ (odds ratio $=2.22$ ), diabetes mellitus (odds ratio $=3.38$ ), total cholesterol level $\geq 240 \mathrm{mg} / \mathrm{dL}$ (odds ratio $=2.23$ ), the last one with a $p$ value of 0.052 (table II).

Among women, no significant association between complications of atherosclerosis and the risk factors was observed (table III). However, one may point out the odds ratio values of the following variables: systemic arterial hypertension $\left(\mathrm{OR}=1.89 ; \mathrm{p}=0.056 ; \mathrm{CI}_{95 \%}=0.98-3.64\right)$ and triglycerides level $\geq 250 \mathrm{mg} / \mathrm{dL}\left(\mathrm{OR}=2.02 ; \mathrm{p}=0.095 ; \mathrm{CI}_{95 \%}=0.89-4.63\right)$.

After adjustment of the variables to the regression model (table IV), we observed that in the total of the elderly patients, by the decreasing order of the odds ratio values, the risk factors for atherosclerotic complications were: triglycerides level $\geq 250 \mathrm{mg} / \mathrm{dL}$ (odds ratio $=2.27$ ), systemic arterial hypertension (odds ratio $=2.17$ ), and male sex (odds ratio $=2.14$ ).

For the men, the risk factors were LDL-cholesterol level $\geq 160 \mathrm{mg} / \mathrm{dL}$ (odds ratio $=2.82$ ), diabetes mellitus (odds ratio $=$ 2.57), HDL-cholesterol level $<35 \mathrm{mg} / \mathrm{dL}$ (odds ratio = 2.17), and systemic arterial hypertension (odds ratio $=2.09$ ); for the women, the risk factors were: triglycerides level $\geq 250 \mathrm{mg} / \mathrm{dL}$ (odds ratio $=2.17$ ) and systemic arterial hypertension (odds ratio $=1.97$ ).

As for the adequacy of each one of the three models of logistic regression, we found that the likelihood ratio test for the final model of the total of the elderly patients was $22.73(\mathrm{p}=0.0000), 19.02(\mathrm{p}=0.0008)$ for the men, and 6.99

\begin{tabular}{|c|c|c|c|c|c|c|c|}
\hline \multirow[t]{2}{*}{ Variables } & \multicolumn{2}{|c|}{ Total } & \multicolumn{5}{|c|}{ Complications of ahterosclerosis } \\
\hline & $\mathrm{N}^{\mathrm{o}}$ & $\%$ & $\mathrm{~N}^{\circ}$ & $\%$ & OR & $\rho$ & $\mathrm{CI}_{95 \%}$ \\
\hline \multicolumn{8}{|l|}{ Sex } \\
\hline Female & 364 & 70.5 & 65 & 17.9 & 1 & & \\
\hline Male & 152 & 29.5 & 45 & 29.6 & 1.93 & 0.003 & $1.22-3.07$ \\
\hline \multicolumn{8}{|l|}{ SAH } \\
\hline$<160$ e/ou 95 & 168 & 32.6 & 24 & 14.3 & 1 & & \\
\hline$\geq 160$ e/ou 95 & 348 & 67.4 & 86 & 24.7 & 1.97 & 0.007 & $1.20-3.23$ \\
\hline \multicolumn{8}{|l|}{$\mathrm{TC}$} \\
\hline$<240 \mathrm{mg} / \mathrm{dl}$ & 352 & 68.2 & 74 & 21.0 & 1 & & \\
\hline$\geq 240 \mathrm{mg} / \mathrm{dl}$ & 164 & 31.8 & 36 & 22.0 & 1.06 & 0.811 & $0.67-1.66$ \\
\hline \multicolumn{8}{|l|}{ LDL-C } \\
\hline$<160 \mathrm{mg} / \mathrm{dl}$ & 338 & 65.5 & 67 & 19.8 & 1 & & \\
\hline$\geq 160 \mathrm{mg} / \mathrm{dl}$ & 178 & 34.5 & 43 & 24.2 & 1.29 & 0.254 & $0.83-2.00$ \\
\hline \multicolumn{8}{|l|}{ HDL-C } \\
\hline$\geq 35 \mathrm{mg} / \mathrm{dl}$ & 442 & 85.7 & 88 & 19.9 & 1 & & \\
\hline$<35 \mathrm{mg} / \mathrm{dl}$ & 74 & 14.3 & 22 & 29.7 & 1.70 & 0.056 & $0.95-3.05$ \\
\hline \multicolumn{8}{|l|}{ Triglycerides } \\
\hline$<250 \mathrm{mg} / \mathrm{dl}$ & 475 & 92.0 & 96 & 20.2 & 1 & & \\
\hline$\geq 250 \mathrm{mg} / \mathrm{dl}$ & 41 & 8.0 & 14 & 34.2 & 2.05 & 0.040 & $1.03-4.05$ \\
\hline \multicolumn{8}{|l|}{ Diabetes mellitus } \\
\hline Absent & 416 & 80.6 & 81 & 19.5 & 1 & & \\
\hline Present & 100 & 19.4 & 29 & 29.0 & 1.69 & 0.038 & $1.03-2.77$ \\
\hline \multicolumn{8}{|l|}{ Tabacco smoking } \\
\hline No & 477 & 92.4 & 102 & 21.4 & 1 & & \\
\hline Yes & 39 & 7.6 & 8 & 20.5 & 0.95 & 0.898 & $0.42-2.13$ \\
\hline \multicolumn{8}{|l|}{ BMI } \\
\hline$\leq 27.5$ & 308 & 59.7 & 63 & 20.5 & 1 & & \\
\hline$>27.5$ & 208 & 40.3 & 47 & 22.6 & 1.14 & 0.560 & $0.74-1.74$ \\
\hline
\end{tabular}




\begin{tabular}{|c|c|c|c|c|c|c|c|}
\hline \multirow[t]{2}{*}{ Variables } & \multicolumn{2}{|c|}{ Total } & \multicolumn{5}{|c|}{ Complications of atherosclerosis } \\
\hline & $\mathrm{N}^{\circ}$ & $\%$ & $\mathrm{~N}^{\mathrm{o}}$ & $\%$ & OR & $\rho$ & $\mathrm{IC}_{95 \%}$ \\
\hline \multicolumn{8}{|l|}{$\mathrm{SAH}$} \\
\hline$<160 \times 95$ & 59 & 38.8 & 11 & 18.6 & 1 & & \\
\hline$\geq 160 \times 95$ & 93 & 61.2 & 34 & 36.6 & 2.51 & 0.020 & $1.53-5.48$ \\
\hline \multicolumn{8}{|l|}{$\mathrm{TC}$} \\
\hline$<240 \mathrm{mg} / \mathrm{dl}$ & 120 & 79.0 & 31 & 25.8 & 1 & & \\
\hline$\geq 240 \mathrm{mg} / \mathrm{dl}$ & 32 & 21.1 & 14 & 43.8 & 2.23 & 0,052 & $0.99-5.02$ \\
\hline \multicolumn{8}{|l|}{ LDL-C } \\
\hline$<160 \mathrm{mg} / \mathrm{dl}$ & 112 & 73.7 & 28 & 25.0 & 1 & & \\
\hline$\geq 160 \mathrm{mg} / \mathrm{dl}$ & 40 & 26.3 & 17 & 42.5 & 2.22 & 0.040 & $1.04-4.74$ \\
\hline \multicolumn{8}{|l|}{ HDL-C } \\
\hline$\geq 35 \mathrm{mg} / \mathrm{dl}$ & 122 & 80.3 & 32 & 26.2 & 1 & & \\
\hline$<35 \mathrm{mg} / \mathrm{dl}$ & 30 & 19,7 & 13 & $43 . .3$ & 1.30 & 0.070 & $0.94-1.81$ \\
\hline \multicolumn{8}{|l|}{ Triglycerides } \\
\hline$<250 \mathrm{mg} / \mathrm{dl}$ & 142 & 93.4 & 40 & 28.2 & 1 & & \\
\hline$\geq 250 \mathrm{mg} / \mathrm{dl}$ & 10 & 6.6 & 5 & 50.0 & 2.55 & 0.156 & $0.70-9.28$ \\
\hline \multicolumn{8}{|l|}{ DM } \\
\hline Absent & 121 & 79.6 & 29 & 23.9 & 1 & & \\
\hline Present & 31 & 20.4 & 16 & 51.6 & 3.38 & 0.004 & $1.49-7.67$ \\
\hline \multicolumn{8}{|l|}{ Tobacco smoking } \\
\hline No & 135 & 88.8 & 41 & 30.4 & 1 & & \\
\hline Yes & 17 & 11.2 & 4 & 23.5 & 0.71 & 0.562 & $0.22-2.29$ \\
\hline \multicolumn{8}{|l|}{ BMI } \\
\hline$\leq 27.5$ & 104 & 68.4 & 29 & 27.9 & 1 & & \\
\hline$>27.5$ & 48 & 31.6 & 16 & 33.3 & 1.29 & 0.494 & $0.62-2.70$ \\
\hline
\end{tabular}

\begin{tabular}{|c|c|c|c|c|c|c|c|}
\hline \multirow[t]{2}{*}{ Variables } & \multicolumn{2}{|c|}{ Total } & \multicolumn{5}{|c|}{ Complications of atherosclerosis } \\
\hline & $\mathrm{N}^{\circ}$ & $\%$ & $\mathrm{~N}^{\circ}$ & $\%$ & OR & $\rho$ & $\mathrm{IC}_{95 \%}$ \\
\hline \multicolumn{8}{|l|}{$\mathrm{SAH}$} \\
\hline$<160 \times 95$ & 109 & 30.0 & 13 & 11.9 & 1 & & \\
\hline$\geq 160 \times 95$ & 255 & 70.1 & 52 & 20.4 & 1.89 & 0.056 & $0.98-3.64$ \\
\hline \multicolumn{8}{|l|}{$\mathrm{TC}$} \\
\hline$<240 \mathrm{mg} / \mathrm{dl}$ & 232 & 63.7 & 43 & 18.5 & 1 & & \\
\hline$\geq 240 \mathrm{mg} / \mathrm{dl}$ & 132 & 36.3 & 22 & 16.7 & 0.88 & 0.655 & $0.50-1.55$ \\
\hline \multicolumn{8}{|l|}{ LDL-C } \\
\hline$<160 \mathrm{mg} / \mathrm{dl}$ & 226 & 62.1 & 39 & 17.3 & 1 & & \\
\hline$\geq 160 \mathrm{mg} / \mathrm{dl}$ & 138 & 37.9 & 26 & 18.8 & 2.11 & 0.702 & $0.64-1.93$ \\
\hline \multicolumn{8}{|l|}{ HDL-C } \\
\hline$\geq 35 \mathrm{mg} / \mathrm{dl}$ & 320 & 87.9 & 56 & 17.5 & 1 & & \\
\hline$<35 \mathrm{mg} / \mathrm{dl}$ & 44 & 12.1 & 9 & 20.5 & 1.21 & 0.632 & $0.51-2.81$ \\
\hline \multicolumn{8}{|l|}{ Trigycerides } \\
\hline$<250 \mathrm{mg} / \mathrm{dl}$ & 333 & 91.5 & 56 & 16.8 & 1 & & \\
\hline$\geq 250 \mathrm{mg} / \mathrm{dl}$ & 31 & 8.5 & 9 & 29.0 & 2.02 & 0.095 & $0.89-4.63$ \\
\hline \multicolumn{8}{|l|}{$\mathrm{DM}$} \\
\hline Absent & 295 & 81.0 & 52 & 17.6 & 1 & & \\
\hline Present & 69 & 19.0 & 13 & 18.8 & 1.08 & 0.813 & $0.55-2.13$ \\
\hline \multicolumn{8}{|l|}{ Tobacco smoking } \\
\hline No & 342 & 94.0 & 61 & 17.8 & 1 & & \\
\hline Yes & 22 & 6.0 & 4 & 18.2 & 1.02 & 0.967 & $0.33-3.13$ \\
\hline \multicolumn{8}{|l|}{ BMI } \\
\hline$\leq 27.5$ & 204 & 56.0 & 34 & 16.7 & 1 & & \\
\hline$>27.5$ & 160 & 44.0 & 31 & 19.4 & 1.20 & 0.503 & $0.70-2.06$ \\
\hline $\begin{array}{l}\text { CI- confidence inter } \\
\text { mellitus; BMI - body }\end{array}$ & . & . & & - & I. & IDL-ch & ; DM- diab \\
\hline
\end{tabular}


$(\mathrm{p}=0.0304)$ for the women. Therefore, all the likelihood ratio test values were significant, permitting the affirmative that the models were adequate.

This significance of the likelihood ratio test in the three models of logistic regression was an important criterion for identifying the variables considered risk factors for of-atherosclerosis. Another classic criterion was the significance of the variable individually, in our case by the $p$ value of Wald (table IV).

The identification of the risk factors was accomplished, therefore, by the interaction of the above two criteria, plus the capacity of the variable to influence the odds ratio of the others, with its removal or inclusion in the model.

\section{Discussion}

Identification of risk factors for atherosclerosis is essential for the adoption of preventive measures. This study evaluated 516 elderly outpatients of both sexes, in order to determine the impact of systemic arterial hypertension, dyslipidemia, diabetes mellitus, tobacco smoking, and obesity, considered risk factors of cardinal importance that can be controlled or even removed.

Among the individuals analyzed, $21.3 \%$ presented with at least one complication of atherosclerosis. Although in this age group, the prevalence of atherosclerotic disease has shown an important increase in women ${ }^{4-7}$, this study showed that after age 60 a significantly greater prevalence of complications of atherosclerosis persists among men (29.6\% x 17.9\%; $\left.\mathrm{OR}=1.93 ; \mathrm{CI}_{95 \%}=1.22-3.07\right)$.

Systemic arterial hypertension was the most prevalent of the risk factors analyzed, affecting $61.2 \%$ of the men and $70.1 \%$ of the women, and the difference in prevalence between the two sexes was statistically significant. These values were similar to those observed by the National Health and Nutrition Examination Survey (NHANES-II) ${ }^{21,22}$ in the United States where the authors, using the same diagnostic criteria, observed in elderly patients systemic arterial hypertension in $59.2 \%$ and $66.2 \%$ of white men and women, and in $67.1 \%$ and $82.9 \%$ of black men and women, respectively.

Systemic arterial hypertension is considered one of the most important causes of morbidity and mortality in the adult population of the civilized world, both by its high prevalence and by its complications.

In the Framingham Study, higher morbidity and mortality by cardiovascular and cerebrovascular disease were found in hypertensive patients, but the risk was lower in the elderly ${ }^{22,23}$. Comparing the elderly patients of both sexes, Hall ${ }^{24}$ observed that with the same level of blood pressure, the risk of atherosclerotic complications was greater in men.

In our study, the importance of systemic arterial hypertension as a risk factor for atherosclerosis and its complications was demonstrated by univariate analysis and confirmed by multivariate analysis both for the total of the elderly patients and for the men and the women separately. Thus, systemic arterial hypertension was the only factors that proved to be of risk in the three groups of subjects studied. This fact, along with the high prevalence of systemic arterial hypertension, shows the great importance of this illness as a cause of atherosclerotic complications in the elderly.

The plasma lipids as risk factors for atherosclerotic disease have been extensively studied in young and middleaged adults. However, few investigations have been conducted in the elderly ${ }^{3,8.9 .25}$.

The prevalences of total cholesterol and LDL-cholesterol were significantly greater among women. These results are

\begin{tabular}{|c|c|c|c|}
\hline \multirow[t]{2}{*}{ Fatores } & \multicolumn{2}{|c|}{ Complications of atherosclerosis } & \multirow[b]{2}{*}{$\mathrm{IC}_{95 \%}$} \\
\hline & OR & $\rho$ & \\
\hline \multicolumn{4}{|c|}{ All the elderly patients } \\
\hline Sex & 2.14 & 0.001 & $1.36-3.36$ \\
\hline Systemic arterial hypertension & 2.17 & 0.003 & $1.31-3.61$ \\
\hline Diabetes mellitus & 1.43 & 0.175 & $0.85-2.39$ \\
\hline Triglycerides $\geq 250 \mathrm{mg} / \mathrm{dl}$ & 2.27 & 0.023 & $1.12-4.59$ \\
\hline HDL-cholesterol <35mg/dl & 1.82 & 0.350 & $0.63-4.02$ \\
\hline LDL-cholesterol $\geq 160 \mathrm{mg} / \mathrm{dl}$ & 1.42 & 0.125 & $0.91-2.24$ \\
\hline \multirow[t]{2}{*}{ Body mass index $>27.5$} & 1.14 & 0.574 & $0.73-1.78$ \\
\hline & \multicolumn{3}{|c|}{ Elderly men } \\
\hline Diabetes mellitus & 2.57 & 0.034 & $1.08-6.16$ \\
\hline Systemic arterial hypertension & 2.09 & 0.085 & $0.90-4.84$ \\
\hline LDL-cholesterol $\geq 160 \mathrm{mg} / \mathrm{dl}$ & 2.82 & 0.015 & $1.23-6.46$ \\
\hline Total cholesterol $\geq 240 \mathrm{mg} / \mathrm{dl}$ & 1.30 & 0.646 & $0.43-3.93$ \\
\hline HDL-cholesterol <35mg/dl & 2.17 & 0.094 & $0.86-5.39$ \\
\hline Triglycerides $\geq 250 \mathrm{mg} / \mathrm{dl}$ & 1.50 & 0.583 & $0.36-6.30$ \\
\hline \multirow[t]{2}{*}{ Body mass index $>27.5$} & 0.82 & 0.641 & $0.36-1.87$ \\
\hline & rly wo & & \\
\hline Systemic arterial hypertension & 1.97 & 0.044 & $1.02-3.81$ \\
\hline Triglycerides $\geq 250 \mathrm{mg} / \mathrm{dl}$ & 2.17 & 0.069 & $0.94-5.03$ \\
\hline Body mass index $>27.5$ & 1.15 & 0.615 & $0.66-1.99$ \\
\hline
\end{tabular}


in agreement with a previous study carried out in the Geriatric Service that showed that total cholesterol and LDL-cholesterol increase in both sexes with advancing age, but mainly in women ${ }^{25}$.

In our study we observed by univariate analysis that total cholesterol $\geq 240 \mathrm{mg} / \mathrm{dL}$ and LDL-cholesterol $\geq 160 \mathrm{mg} /$ $\mathrm{dL}$ were risk factors for complications of atherosclerosis among men, but not among women, nor in the whole group of elderly patients. Multivariate analysis partially confirmed these results, because only LDL-cholesterol was shown to be a risk - factor in men.

The role of total cholesterol and LDL-cholesterol as risk factors for atherosclerosis in the elderly is a subject open for discussion ${ }^{26}$. Several studies have reached the conclusion that they are important risk factors for coronary artery disease; however, these studies also agree on their lesser impact in the elderly as compared with middle-aged subjects ${ }^{12,27-31}$.

Papaléo Netto et al ${ }^{9}$ compared total cholesterol and LDL-cholesterol levels of 31 aged patients of both sexes with atherosclerotic complications with total cholesterol and LDL- cholesterol levels of a group of healthy elderly individuals and found no significant difference between the two groups.

Krumholz et al ${ }^{11}$ followed 997 individuals of both sexes 70 years or older for four years and did not find any correlation between total cholesterol $\geq 240 \mathrm{mg} / \mathrm{dL}$ and higher mortality due to coronary artery disease or more frequent hospital admissions for acute myocardial infarction and unstable angina.

According to La Rosa ${ }^{28}$ and Crouse ${ }^{29}$, LDL-cholesterol may be more harmful to men. Studies performed in primates suggest that the presence of circulating estrogen in women could may interfere with the uptake of LDL-cholesterol by the artery wall, which may be related to its antioxidant effect ${ }^{32}$.

Capurso ${ }^{33}$ believes that the conflicting results obtained by several investigators may be caused by the fact that in the elderly, dyslipidemia is frequently related to nongenetic causes, such as hypothyroidism and the use of drugs like diuretics. These secondary forms of dyslipidemia could be less related to cardiovascular risk, because they are of later onset and thus exert atherogenic effect for a shorter period of time.

In $19.7 \%$ of men and $12.1 \%$ of women, plasma HDLcholesterol was below $35 \mathrm{mg} / \mathrm{dL}$, and this difference was statistically significant.

In a previous study of the Geriatric Service, Figueira et al ${ }^{25}$ observed that HDL-cholesterol levels diminished with age in both sexes, but more markedly in males.

The analysis of the importance of HDL-cholesterol as a risk factor for atherosclerotic vascular disease in the elderly has been done in several studies ${ }^{34-37}$. In the Framingham study, HDL-cholesterol $<35 \mathrm{mg} / \mathrm{dL}$ correlated with a greater prevalence of cardiovascular disease in elderly patients of both sexes ${ }^{34}$. According to La Rosa ${ }^{28,35}$ the HDLcholesterol levels, usually higher in women, could be one of the reasons why they have a lesser risk of atherosclerotic complications than men. On the other hand, the Bronx Aging Study showed HDL-cholesterol $<35 \mathrm{mg} / \mathrm{dL}$ as an important risk factor for coronary artery disease only in men ${ }^{36}$.

In our study, we observed that HDL-cholesterol $<35 \mathrm{mg} / \mathrm{dL}$ corresponded to a greater prevalence of atherosclerotic complications in men $(43.3 \%)$ as compared with women $(20.5 \%)$. The comparison, by univariate analysis, between the subjects with HDL-cholesterol $<$ and $\geq 35 / \mathrm{dL}$, as to the presence of atherosclerotic complications did not show any difference in the women, but in the men the prevalences of complications were $43.3 \%$ and $26.2 \%$, respectively. The comparative study by multivariate analysis also showed that HDL-cholesterol $<35 \mathrm{mg} / \mathrm{dL}$ was a risk factor for atherosclerotic complications only in men.

It has been demonstrated by comparing normal individuals, both young and aged, that triglycerides rise significantly during the aging process in both sexes ${ }^{25}$. In our study, only $8.0 \%$ of the patients showed triglycerides levels of $\geq 250 \mathrm{mg} / \mathrm{dL}$, with no significant difference between men and women.

The importance of triglycerides as a risk factor for atherosclerosis, both in elderly and middle-aged individuals, and its complications has been debated in the literature ${ }^{36,38}$, with a good deal of controversy. Recently, several studies have called attention to triglycerides as an important risk factor of cardiovascular disease, independently of the association with other factors such as diabetes mellitus and low HDL-cholesterol ${ }^{39-41}$.

In our study, analyzing the total of patients by univariate analysis, we observed a significant association between triglycerides $\geq 250 \mathrm{mg} / \mathrm{dL}$ and atherosclerotic complications. When the male and female subjects were analyzed separately, in spite of the greater prevalence of atherosclerotic complications in those with triglycerides $\geq 250 \mathrm{mg} / \mathrm{dL}$ in relation to those with triglycerides $<250 \mathrm{mg} / \mathrm{dL}$ (respectively $50.0 \% \times 28.2 \%$ and $29.0 \% \times 16.8 \%$ ), no significant difference was noted. However, we have to emphasize the odds ratio value observed in women $\left(\mathrm{OR}=2.02 ; \mathrm{p}=0.095 ; \mathrm{CI}_{95 \%}=0.89\right.$ 4.63). Multivariate analysis confirmed these results, maintaining triglycerides $\geq 250 \mathrm{mg} / \mathrm{dL}$ as a risk factor for the total of elderly patients and for the women.

Diabetes mellitus was diagnosed in $20.4 \%$ of the men and $19.0 \%$ of the women, with no significant difference between the two sexes.

In the Framingham Study, the risk of death by cardiovascular disease was 1.7 times greater in men and 3.3 times greater in women with diabetes, when compared with that in nondiabetic patients ${ }^{42}$. The Tecumseh Study showed even more striking results, with the risk of atherosclerotic complications 1.9 times greater in diabetic men and 5.3 times greater in diabetic women, when compared with nondiabetic patients ${ }^{43}$.

In the present study, we showed by univariate analysis a significant association between diabetes mellitus and the presence of atherosclerotic complications among the patients as a whole and among the men separately; this was confirmed by multivariate analysis only in the men. In the women, univariate analysis showed that the prevalence of 
atherosclerotic complications among diabetic and nondiabetic patients was practically equal $(18.8 \%$ x $17.6 \%$; OR = $1.08 ; \mathrm{p}=0.813 ; \mathrm{CI}_{95 \%}=0.55-2.13$ ).

The fact that diabetes mellitus, in spite of its high prevalence (19.0\%), did not prove to be a risk factor among the women is in disagreement with the data in the literature, but this could mean that, among the elderly women of our group, other risk factors such as age causing senile atherosclerosis, and estrogen deficiency, may have been of primordial importance.

As for tobacco smoking, the behavior of the $516 \mathrm{el}-$ derly patients varied a great deal. Many were past smokers but had abandoned the smoking habit for variable periods of time. The number of cigarettes consumed per day also had great variation. For these reasons, two groups were considered: a) smokers, made up of patients who were smoking at the time of the interview, and b) nonsmokers, made up of patients who had never smokers.

It was shown that the prevalence of smokers in this outpatient population was low (7.6\%), with a significant predominance of the men $(11.2 \%)$ in relation to the women $(6.0 \%)$.

The smoking habit is frequently associated with other factors related to atherosclerosis and its complications, such as lower HDL- cholesterol levels, elevation of blood viscosity, hyper-fibrinogenemia, greater platelet aggregation, and anti-estrogen effect ${ }^{44,45}$.

The role of tobacco smoking as a risk factor was demonstrated in experimental, clinical, and anatomopathological studies. The deleterious changes caused by tobacco smoking are proportional to the number of cigarettes consumed, the duration of the smoking habit and the age of onset of smoking 12,46,47.

Among elderly smoker the risk of atherosclerotic complications seems lower than that observed in middleaged smokers, but still higher than that in elderly nonsmokers ${ }^{12,45}$.

The low prevalence of smokers among the elderly patients in our study, much lower than that observed in younger age groups, could mean that the patients more susceptible to the harmful effects of smoking had complications and died prematurely. This supposition plus the fact that during the aging process other factors such as age itself may predominate could explain why smokers and nonsmokers of both sexes showed no difference in the prevalence of atherosclerotic complications.

The relationship between obesity and atherosclerotic complications has been a subject of controversy. Several studies have suggested this association; however, only a few demonstrated a specific effect of obesity as a risk factor, because it is usually associated with other factors, such as systemic arterial hypertension, dyslipidemia and diabetes mellitus.

Our study observed that obesity, defined by a body mass index $>27.5$, was present in $31.6 \%$ of the men and $44.0 \%$ of the women; this difference was statistically significant.

By univariate analysis, no significant difference was found between complications of atherosclerosis in obese and nonobese patients in both sexes. It is possible that an analysis directed to the distribution of body fat could yield a different result, because individuals with abdominal obesity present with a greater prevalence of complications than those with gluteo-femoral obesity ${ }^{48,49}$.

In summary, among the elderly patients analyzed in the present study, the prevalence of atherosclerotic complications was significantly greater in the men compared with that in the women.

The data obtained showed that in the elderly; the risk factors for atherosclerosis and its complications have a different prevalence between males and females.

Comparative analysis revealed that systemic arterial hypertension, total cholesterol $\geq 240 \mathrm{mg} / \mathrm{dL}$, LDL-cholesterol $\geq 160 \mathrm{mg} / \mathrm{dL}$, and body mass index $>27.5$ were more frequent in the women, HDL-cholesterol $<35 \mathrm{mg} / \mathrm{dL}$ and tobacco smoking were more frequent in the men, and no difference was noted in relation to triglycerides $\geq 250 \mathrm{mg} / \mathrm{dL}$ and diabetes mellitus.

The risk of complications of atherosclerosis in relation to each one of the factors analyzed also showed an important difference between elderly men and women. Thus, LDLcholesterol $\geq 160 \mathrm{mg} / \mathrm{dL}$, HDL-cholesterol $<35 \mathrm{mg} / \mathrm{dL}$, diabetes mellitus, and systemic arterial hypertension were risk factors for the men, but triglycerides $\geq 250 \mathrm{mg} / \mathrm{dL}$ and systemic arterial hypertension were risk factors for the women.

Based on these findings, we can affirm that the factors considered of risk for atherosclerosis and its complications in the elderly have different consequences in men and women. Therefore, the evaluation of these factors should be done by different weights in each sex, so that adequate preventive and therapeutic measures can be taken in the respective situation.

The results of this investigation also suggest, confirming the opinion of other authors ${ }^{2,50}$, that the order of importance of the risk factors can change with the aging process, as in the case of tobacco smoking for example.

Undoubtedly, further investigations are necessary to evaluate adequately the importance of the risk factors for atherosclerosis in elderly patients, comparing people of different age groups, including the very elderly, studying patients of different socio-economic conditions, and analyzing the impact of preventive and therapeutic measures on the prevalence of the risk factors and their complications. 


\section{References}

1. Karvonen MJ. Determinants of cardiovascular diseases in the elderly. Ann Intern Med 1989;21:3-12.

2. Aronow WS. Cardiac risk factors: Still important in the elderly. Geriatrics 1990; 45 (1): 71-80.

3. Fletcher AE, Bulpitt CJ. Epidemiological aspects of cardiovascular disease in the elderly. J Hypertens 1992; 10(suppl 2): S 51-8.

4. Lemer DJ, Kannel WB. Patterns in coronary heart disease - Morbidity and mortality in the sexes: a 26-year follow-up of the Framingham population. Am Heart J 1986; 111: 383-90.

5. Castelli WP. Cardiovascular disease in women. Am J Obstet Gynecol 1988; 158 : 1552-60.

6. Kuhn FE, Rackley CE. Coronary artery disease in women. Arch Int Med 1993; 153: 2626-36.

7. Fundação Sistema Estadual de Análise de Dados (SEADE). O idoso na Grande São Paulo. São Paulo 1990: 138-41.

8. Wenger NK. Exclusion of the elderly and woman from coronary trials. JAMA 1992; 268: 1460-1.

9. Papaléo Netto M, Carvalho FilhoET, Figueira JL, et al. Alterações lipídicas em idosos portadores de complicações da aterosclerose. Arq Bras Card 1988; 50: 11-4.

10. Benfante R, Reed D. Is elevated serum cholesterol level a risk factor for coronary heart disease in the elderly? JAMA 1990; 263: 393-6.

11. Krumholz HM, Seeman TE, Merrill SS, et al. Lack of association between cholesterol and coronary heart disease mortality and morbidity and all-cause mortality in persons older than 70 years. JAMA 1993; 272: 1335-40.

12. Wenger NK. Preventive cardiology in the elderly. Current Opinion in Cardiology 1997; 12: 195-201.

13. Reed G, Anderson RJ. Epidemiology and risk of hypertension in the elderly. Clin Ther 1982; 5(spec): 1-8.

14. Allain CC, Poon LS, Chan CSK, Richmond W, Fu PC. Enzymatic determination of total serum cholesterol. Clin Chem 1974; 20: 470-4.

15. Warnick GR, Albers JJ. A comprehensive evaluation of heparin manganese precipitation procedure for estimating high density lipoprotein cholesterol. J Lipid Res 1973; 19: 65-8.

16. Friedewald WT, Levy RI, Fredrickson DS. Estimation of the concentration of low-density lipoprotein cholesterol in plasma without use of the preparative ultracentrifuge. Clin Chem 1972; 18: 499-502.

17. Trinder P. Determination of glucose in blood using glucose oxidase with an alternative oxygen acceptor. Ann Clin Biochem 1969; 6: 24.

18. Keys A, Fidanza F, Karvonen MJ, Kimura N, Taylor HL. Indices of relative weight and obesity. J. Chron Dis 1972; 25: 329-43.

19. Lamon-Fava S, Wilson PWF, Schaefer EJ. Impact of body mass index on coronary heart disease risk factors in men and women. The Framingham Offspring Study. Arterioscler Thromb Vasc Biol 1996; 16: 1509-15.

20. Campos Filho N, FrancoEL. MULTLR-A microcomputer program formultiple logistic regression by unconditional and conditional maximum likelihood methods. Am J Epidemiol 1989; 129: 439-44.

21. Joint National Committee on Detection, Evaluation, and Treatment of High Blood Pressure - The 1992 Report of the Joint National Committee on Detection, Evaluation, and Treatment of High Blood Pressure (JNC-V). Arch Intern Med 1993; 153: 154-83.

22. Messerli FH, Grodzicki T. Hypertension and coronary artery disease in the elderly. Clin Geriatr Med 1996; 12: 41-55.

23. Levy D, Kannel WB. Cardiovascular risks: New insights from Framingham. Am Heart J 1988; 16: 266-72.

24. Hall PM. Hypertension in women. Cardiology 1990; 77(suppl 2): 25-30.

25. Figueira JL, Papaléo Netto M, Carvalho Filho ET, et al. Perfil lipídico em indivíduos idosos normais. Arq Bras Cardiol 1987; 48: 77-81.
26. Hulley SB, Newman TB. Cholesterol in the elderly. Is it important? JAMA 1994; 272: $1372-4$

27. Bruckert E, Delahaye F, Richard JL, Emmerich J, Thomas D. Hyperlipidemia chez le sujet âgé de plus de 60 ans. Arch Mal Coeur 1992; 85(III) : 79-82.

28. La Rosa JC. Management of postmenopausal women who have hyperlipidemia. Am J Med 1994; 96(suppl 6A): 19-24.

29. Crouse JR. Gender, lipoproteins, diet and cardiovascular risk. Lancet 1989; 1: 318-20.

30. Aronow WS, Ahn C. Risk factors for new coronary events in a large cohort of very elderly patients with and without coronary artery disease. Am J Cardiol 1996; 77: 864-6.

31. Corti M-C, Guralnik JM, Salive ME, et al. Clarifying the direct relation between total cholesterol levels and death from coronary heart disease in older persons. Ann Intern Med 1997; 126: 753-60.

32. Wagner JD, Clarkson TB, St Clair RW, Schwenke DC, Adams MR. Estrogen replacement therapy and coronary artery atherogenesis in surgically post-menopausal cynomolgus monkeys. Circulation 1989; 80(suppl II): 331 .

33. Capurso A. Lipid metabolism and cardiovascular risk: Should hypercholesterolemia be treated in the elderly? J Hypertens 1992; 10(suppl.2): 65-8.

34. Annel WB, Brand FN. Cardiovascular risk factors in the elderly. In: Andres R, Bierman EL, Hazzard WR, eds. Principles of Geriatric Medicine. New York: McGraw-Hill, 1985: 104-19.

35. La Rosa JC. Dyslipoproteinemia in women and elderly. Med Clin North Am 1994; 78: 163-80

36. Zimetbaum P, Frishman WH, Ooi WL, et al. Plasma lipids and lipoproteins and the incidence of cardiovascular disease in the very elderly. The Bronx Aging Study. Arterioscler Thromb 1992; 12: 416-23.

37. Corti M-C, Gukralnik JM, Salive ME, et al. HDL cholesterol predicts coronary heart disease mortality in older persons. JAMA 1995; 274: 539-44.

38. Leaf DA. Lipid disorders: Applying new guidelines to your older patients. Geriatrics $1994 ; 49(5): 35-41$.

39. Jeppesen J, Hein HO, Suadecani P, Gyntelberg F. Triglyceride concentration and ischemic heart disease. Circulation 1998; 97: 1029-36.

40. Austin MA, Hokanson JE, Edward KL. Hypertriglyceridemia as a cardiovascular risk factor. Am J Cardiol 1998; 81: 7-12.

41. Gotto AM. Triglyceride. The forgotten risk factor. Circulation 1998; 97: 1027-8.

42. Kannel WB. Lipids, diabetes, and coronary heart disease: Insights from the Framingham Study. Am Heart J 1985; 110: 1100-7.

43. Epstein FH, Ostrander Jr LD, Johnson BC, et al. Epidemiological studies of cardiovascular disease in a total community: Tecumseh, Michigan. Ann Intern Med 1965; 62: 1170-87.

44. Laustiola KE. Atherothrombotic mechanisms in smoking. J Intern Med 1991; 230: 469-70.

45. Khaw KT, Tazuke S, Barrett-Connor E. Cigarette smoking and levels of adrenal androgens in post menopausal women. N Engl J Med 1988; 318: 1705-8.

46. Jajich CL, Ostfeld AM, Freeman Jr DH. Smoking and coronary heart disease mortality in the elderly. JAMA 1984; 252: 2831-4.

47. Vogt MT, Cauley JA, Scott JC, Kuller LH, Browner WS. Smoking and mortality among older women. Arch Intern Med 1996; 156: 630-6.

48. Despres JP, Moorjani S, Lupien PJ, et al. Regional distribution of body fat, plasma lipoproteins and cardiovascular disease. Arteriosclerosis 1990; 10: 497-511

49. Seidell JC, Cigolini M, Charzewska J, et al. Fat distribution and gender differences in serum lipids in men and women from four European communities. Atherosclerosis 1991; 87: 203-10.

50. CasigliaE, Palatini P. Cardiovascular risk factors in the elderly. JHuman Hypertens 1998; 12: 575-81. 